\title{
Medication Choices for Paediatric Epilepsy
}

\author{
Badriyah Shadid Alotaibi* \\ Department of Pharmaceutical Science, College of Pharmacy, Princess Nourah Bint Abdulrahman University, Saudi Arabia
}

Submission: October 02, 2019; Published: October 28, 2019

*Corresponding author: Badriyah Shadid Alotaibi, Assistant professor, Department of Pharmaceutical Science, College of Pharmacy, Princess Nourah Bint Abdulrahman University, Riyadh, Saudi Arabia

\begin{abstract}
The World Health Organization estimates that 50 million people suffer from epilepsy with $50 \%$ of them being children and adolescents. It is well known how epilepsy can adversely affect the development and quality of life of children, but those affected also have a higher mortality risk, ranging up to 9 times that of the general population. These factors lead to an urgent need to understand the various forms of pharmacological treatment and the possible adverse effects that may present as a result of prescribed medications. Each case will be different and requires a personalized plan of treatment. As the number of antiepileptic drugs has swelled over the last two decades, treatment options have likewise grown. It is therefore timely to summarize the traditional epilepsy medications used and to review some of the more recent antiepileptic drugs now at the disposal of the paediatric neurologist with an emphasis on their efficacy and safety.

Keywords: Paediatric epilepsy; Medication; Antiepileptic drugs
\end{abstract}

\section{Introduction}

\section{Background to epilepsy in children}

Epilepsy is a chronic paediatric neurological disorder [1]. It has a tremendous influence upon each sphere of the affected children's lives, especially their physiological, cognitive, psychological, and sociocultural development [2]. In developed countries the prevalence of chronic disease, including epilepsy in children, has increased at an estimated rate of 5 to $30 \%$ [3]. Understanding the aetiology of the disease, and the available pharmacological options is fundamental to the success of epilepsy treatment [4].

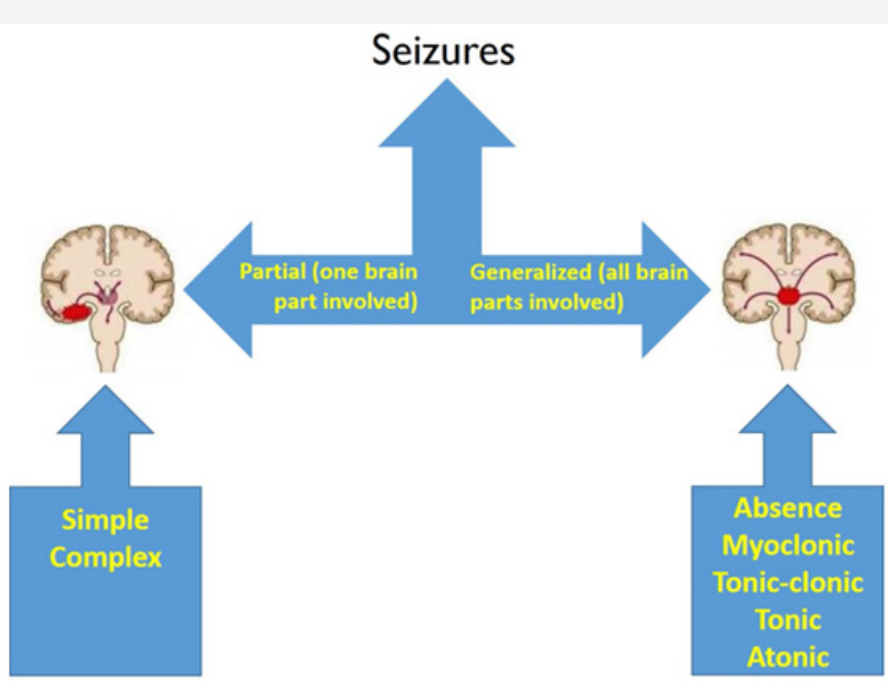

Figure 1: The affected part of the brain and its association with various types of epileptic seizures.

\section{Epilepsy definition and classification}

Epilepsy is currently considered a chronic neurological disorder with a tendency to induce recurrent seizures. It is defined as the occurrence of two or more seizures that are not under the influence of known factors [5]. There are various types of seizures; thus, a precise classification of seizures for epilepsy in children 
is considered a fundamental factor for an appropriate selection of antiepileptic drugs and its prognostic outcome [4]. Based on the affected part and the activity of the brain, epileptic seizures can be divided into generalized and partial seizures [4]. Figure 1 shows various types of seizures based on the affected part of the brain. The most widely used classifications for epileptic seizures are those initially developed by the International League Against Epilepsy (ILAE) in 1981 [6].

Seizures are classified into three general categories:

a) Partial seizures with localized onset,

b) Generalized seizures and

Table 1: Classification of seizures according to the ILAE 1989 (7).

\begin{tabular}{|c|c|}
\hline Seizure Type & Description \\
\hline \multirow{6}{*}{ I. Focal (localisation related or partial) } & Idiopathic epilepsy with age related onset \\
\hline & a. Benign rolandic epilepsy \\
\hline & b. Childhood epilepsy with occipital paroxysms \\
\hline & c. Primary reading epilepsy \\
\hline & Symptomatic epilepsy \\
\hline & Cryptogenic epilepsy \\
\hline \multirow{9}{*}{ II. Generalised } & Idiopathic epilepsy with age related onset \\
\hline & a. Benign neonatal familial convulsions \\
\hline & b. Benign neonatal non-familial convulsions \\
\hline & c. Benign myoclonic epilepsy in infancy \\
\hline & d. Juvenile absence epilepsy \\
\hline & e. Juvenile myoclonic epilepsy \\
\hline & f. Epilepsy with generalised tonic-clonic seizures on \\
\hline & awakening \\
\hline & g. Other idiopathic epilepsies \\
\hline & $\begin{array}{l}\text { Cryptogenic or symptomatic epilepsy } \\
\text { a. West syndrome (infantile spasms) } \\
\text { b. Lennox-Gastaut syndrome (childhood epileptic } \\
\text { encephalopathy) } \\
\text { c. Epilepsy with myoclonic-astatic seizures } \\
\text { d. Epilepsy with myoclonic absence seizures }\end{array}$ \\
\hline & $\begin{array}{l}\text { Symptomatic epilepsy } \\
\text { a. Non-specific syndromes; e.g. early myoclonic } \\
\text { encephalopathy } \\
\text { b. Specific syndromes; i.e. epileptic seizures as a complication of a disease; e.g. } \\
\text { phenylketonuria. }\end{array}$ \\
\hline \multirow[t]{2}{*}{$\begin{array}{l}\text { III. Undetermined epilepsies whether focal or } \\
\text { generalised }\end{array}$} & $\begin{array}{c}\text { With both generalised and focal features } \\
\text { a. Neonatal seizures } \\
\text { b. Severe myoclonic epilepsy in infancy } \\
\text { c. Epilepsy with continuous spike waves during slow-wave sleep } \\
\text { d. Acquired epileptic aphasia } \\
\text { e. Other undetermined epilepsies not defined above }\end{array}$ \\
\hline & Without unequivocal generalised or focal features \\
\hline \multirow[t]{2}{*}{ IV. Special syndromes } & $\begin{array}{l}\text { Febrile convulsions; e.g. febrile convulsions, seizures due to stress or alcohol or sleep } \\
\text { deprivation. }\end{array}$ \\
\hline & Isolated, apparently unprovoked seizures \\
\hline
\end{tabular}

\section{c) Unclassified seizures.}

Generalized seizures can be described as those affecting the whole brain due to changes in electrical activities leading to loss of consciousness. Examples of generalized seizures include absence seizure, myoclonic seizures, clonic seizures, tonic seizures, tonic-clonic seizures and atonic seizures. Partial seizures have two subtypes: Simple partial seizures during which a child remains conscious and complex partial seizures in which a loss of consciousness occurs. In 1989, the ILAE produced a new classification guideline for epilepsy. This classification was based on additional factors which were not given in the previous edition including type of seizure, EEG, pathophysiological, aetiological and prognosis data [7]. Table 1 illustrates the revised classification. 


\section{Clinical assessment}

An in-depth clinical assessment of the history of paediatric patients is essential for an accurate diagnosis of epilepsy [8]. Physical and neurological examination of patients is used to detect the underlying causes of epilepsy disorder.

\section{Investigation}

Commonly used tools for epilepsy investigation include Electroencephalography (EEG), Magnetic Resonance Imaging (MRI) and Computed Tomography (CT) [9]. EEG evaluates the brain function by identifying the epileptic form, which can be achieved by recording the brain's electrical discharge, which is usually excessive [10]. MRI is considered one of the most sensitive neuroimaging procedures for detection of brain structural abnormalities, which might be responsible for epilepsy $[9,10]$. CT is sometimes preferred to MRI for patients with aneurysm clips (small metal clips for blood vessels in the brain), heart pacemakers, acute haematomas in an intracranial site and fractures of the skull [11]. Other diagnostic techniques have been developed for brain functional imaging including magneto encephalography, positron emission tomography (PET), magnetic resonance spectroscopy (MRS) and photon emission computed tomography (PECT) [11].

\section{Epilepsy Treatment}

Treatment options of epilepsy are limited and some of these options remain controversial [12]. Anti-epileptic drugs (AEDs) are the most common and effective treatments of epilepsy disorder. According to Dulac, [12] approximately $75 \%$ of epileptic paediatric patients can be successfully treated by anti-epileptic drugs.

\section{Antiepileptic drugs (AED) generations}

AEDs have been classified into two groups: Conventional (1st generation) AEDs (drugs that were introduced into the United Kingdom market before 1989) and newer (2nd generation) AEDs (introduced after or in 1989) [13,14]. Table 2 illustrates AEDs introduced in the United Kingdom according to their licence dates. Although 1st generation AEDs have drawbacks, including pharmacokinetic non-linearity, lower response rate, drug-drug interactions and higher incidence of adverse events, they have the advantage of longer term history [2]. Thus, their effectiveness in the treatment of seizures, mechanism of actions, pharmacokinetic profiles, drug-drug interactions and side effects are well known [15]. Others feel that these AEDs should be replaced by 2nd generation AEDs, as these more recent medications have multiple mechanisms of action making them more suitable for the treatment of several types of seizures [16]. Furthermore, newer AEDs tend to have a lower incidence of adverse side effects and drug-drug interactions [17]. According to the National Institute for Health and Care Excellence (NICE), the prescription of 2nd generation AEDs accounted for $20 \%$ of the total number of AED prescriptions in 2002 [18] and data from 2017 indicate these numbers continue to climb [19]. Accounting for 2nd generation AEDs, the available number of AEDs has approximately tripled [17], making the medication choice for treatment of certain types of seizures more difficult [17]. As such, a comparison between these agents has become a crucial subject [15].

Table 2: Antiepileptic drugs (AEDs) licenced in the UK.

\begin{tabular}{|c|c|}
\hline Anti-Epileptic Drug & Approval Date in the UK \\
\hline \multicolumn{2}{|c|}{ Conventional $\mathbf{1}^{\text {st }}$ generation) AEDs } \\
\hline Phenobarbital & 1912 \\
\hline Phenytoin & 1938 \\
\hline Primidone & 1952 \\
\hline Ethosuximide & 1955 \\
\hline Carbamazepine & 1965 \\
\hline Sodium valproate & 1973 \\
\hline Clonazepam & 1974 \\
\hline Clobazam & 1979 \\
\hline \multicolumn{2}{|c|}{ Newer $\mathbf{2}^{\text {nd }}$ generation) AEDs } \\
\hline Vigabatrin & 1989 \\
\hline Lamotrigine & 1991 \\
\hline Gabapentin & 1993 \\
\hline Topiramate & 1995 \\
\hline Tiagabine & 1998 \\
\hline Oxcarbazepine & 2000 \\
\hline Levetiracetam & 2000 \\
\hline Pregabalin & 2004 \\
\hline Zonisamide & 2005 \\
\hline
\end{tabular}

\section{Common antiepileptic drugs (AEDs) used in children}

A high percentage of children with epilepsy are affected in infancy or early childhood, and therefore are highly susceptible to epilepsy seizure causing irreversible injury due to their immature brain. Therefore, treatment should be initiated as soon as possible with the main goal of maximising control of seizure attacks and minimising the development of adverse events $[20,21]$. However, treatment using some AEDs is not equally effective for all children and the development of adverse events vary [22] as the required AED dose depends on the child's body weight and the rate of drug metabolism, which can be extremely variable [23]. Some neurologists considered the used of one antiepileptic drug (monotherapy) as a gold standard for management of epilepsy since it usually associated with low incidence rates of adverse events (AE) [24], while others argued that the use of low dose of more than one AED (polytherapy) is effective for treatment of epilepsy, especially with the introduction of newer AEDs that act with various mechanisms [25]. It is generally recommended that the use of polytherapy should be avoided in children unless treatment with monotherapy has failed, as polytherapy can place children at a higher risk of AED toxicity, drug-drug interactions and hinder the evaluation of the effectiveness of individual antiepileptic drugs [26].

This section will review the most commonly used AEDs in children with epilepsy, divided into two groups - conventional $\left(1^{\text {st }}\right.$ generation) and newer ( $2^{\text {nd }}$ generation $)$ AEDs. 


\section{Conventional ( $1^{\text {st }}$ generation) of Antiepileptic Drug Treatment}

Conventional AEDs are considered as the first choice for the treatment of epilepsy in children.2 The most common AEDs in this category are benzodiazepines, including clonazepam, nitrazepam and clobazam, and carbamazepine, ethosuximide, phenobarbital, phenytoin, primidone and valproic acid [27].

\section{Benzodiazepines}

Clonazepam: Clonazepam produces its action by the inhibition of GABA receptors [28]. It is absorbed rapidly following administration via oral, rectal, intramuscular (IM) and intravenous (IV) routes [29]. It possesses high plasma protein binding. Thus, its concentration in the blood can be affected by other drugs that alter protein binding [28]. Its elimination half-life in children ranges between 10 and 15 hours [30]. The onset of action can be seen immediately (within two minutes) after intravenous (IV) dose administration [30]. In paediatrics, clonazepam is commonly administrated as an adjunct for different generalised epileptic seizure treatment [31]. Sedation or drowsiness and behavioural changes were the most common adverse events associated with clonazepam [32].

Nitrazepam: Nitrazepam is used specifically for the treatment of infantile spasms associated with hypsarrhythmia and paediatric patients with Lennox-Gastaut syndromes.2 It controls seizure activity by inhibiting GABA-A receptors [33]. The most common adverse events include hypoxia, vomiting and drowsiness, while the most serious adverse event is aspiration, which may lead to pneumonia and death [34], with the risk of death higher in children younger than four years of age [35].

\section{Carbamazepine}

Carbamazepine (CBZ) inhibits continuous repetitive elevation in neuronal firing frequency by blocking sodium and calcium voltage gated channels [36]. Additionally, there are reports identifying the ability of carbamazepine to modulate neuronal glutaminergic, serotonergic and purinergic effects [37-40]. However, the significance of some of these effects on the clinical effectiveness of CBZ remains unclear [2]. Carbamazepine is a water insoluble drug and absorption rate varies according to formulation types [41]. It is well distributed in the body tissues and approximately $75 \%$ of carbamazepine binds to plasma proteins. It is metabolised by cytochrome P450 enzymes to carbamazepine -10,11-epoxide (active metabolite) in the liver [41] and is more rapidly metabolised in infants [2]. Thus, CBZ activity and toxicity are higher in infants and younger children. Carbamazepine is often used for the treatment of simple and complex partial seizures and generalised tonic-clonic epileptic seizures in children [42]. Carbamazepine appears to be well tolerated in paediatric patients [2]. The most common side effects are skin rash and leukopenia, while ataxia, dizziness, diplopia and vomiting may occur at higher dosages [2].

\section{Phenobarbital (PB)}

Due to its favourable pharmacokinetics and relatively lower toxicity, phenobarbital (PB) remains in use in children [43]. It produces its action via inhibition of GABA-A receptors and enhancement of chloride ion permeability and can inhibit neurotransmitter release by reducing presynaptic neuronal uptake of calcium [16]. It has good bioavailability in children after oral (more than 90\%) and intramuscular (80\%) administrations [44], but lower in neonates and younger infants because of reduced absorption $[2,44]$. Peak plasma levels are reached within one to six hours, while three to nine hours are required in younger children and infants. PB is metabolised by hepatic enzymes to primary inactive metabolite (para hydroxy Phenobarbital) [2]. It has low protein binding (45\%) in children and (25 to 50\%) neonates [45]. Phenobarbital has been used for the treatment of various types of seizures in children, such as generalised tonicclonic, simple partial seizures, simple or complex partial status seizures and juvenile myoclonic seizures [2]. In neonates, PB is still the drug of choice for the treatment of neonatal epileptic seizures. The most common adverse events of phenobarbital are cognitive impairment [46]. Ataxia and sedation are usually associated with administration at high doses. Hyperactivity and irritability have also been reported in paediatric patients [47]. Phenobarbital dependence can occur with sudden discontinuation, which can cause a rebound effect characterised by tremors and an increase in seizure frequency [2].

\section{Phenytoin (PHT)}

The antiepileptic properties of phenytoin (PHT) are related to its ability to inhibit sodium and calcium voltage gate channels [48]. It is highly insoluble in the stomach due to its low $\mathrm{pH}$, while it is absorbed well in the small intestine [49]. The bioavailability of phenytoin after administration as oral suspension is approximately $95 \%[2,49]$. However, this percentage can vary according to the drug formulations. It is highly protein bound (approximately 90\%), with the protein binding lower and more variable in neonates [50]. PHT is metabolised by the liver and has a highly variable clearance rate. Consequently, its plasma concentration can increase disproportionately after a small increment increase in the dose [2]. PHT is effective in the treatment of various epileptic seizures in children, such as generalised tonicclonic seizures and complex partial status epilepticus. Also, it is considered a good choice in the treatment of status epilepticus [51]. The most frequent adverse effects are gingival hyperplasia and hypersensitivity reaction $[2,52]$. Polyneuropathy may develop after a long period of treatment [2].

\section{Valproic acid}

Valproic acid's mechanism of action is still a matter of debate [53]. In general, valproic acid acts by increasing the GABA levels in the brain, thereby increasing succinic semialdehyde. Approximately 70-94\% of valproic acid is bound to plasma protein (mainly to albumin) [54]. Its concentration has an effect on the 
extent of binding (i.e. binding decreases with increasing valproic acid concentration). This effect provides a nonlinear relationship between its plasma concentration and dosage [55]. The volume of distribution ranges between 0.13 to $0.19 \mathrm{~L} / \mathrm{kg}$, [56] and its half-life varies between 9 and 18 hours [57]. However, in patients taking an enzyme inducer such as carbamazepine, the half-life is lower (5-12 hours). It is significant that the elimination rate of valproic acid is faster in children as compared with adults; hence, children need larger dosages per body weight $(\mathrm{kg})$ to achieve therapeutic concentration [57]. Although a small amount can be detected in the urine, valproic acid is almost completely metabolised in the liver [58]. It should be pointed out, however, that valproic acid does pose the greatest risk of congenital malformations, while risks associated 2nd generation drugs such as lamotrigine and levetiracetam are significantly lower. This should be borne in mind when treating adult women who are pregnant or considering pregnancy [59].

\section{Newer ( $2^{\text {nd }}$ generation) Antiepileptic Drugs}

These drugs often possess multiple mechanisms of action, enabling them to be used for treating a broad spectrum of epileptic seizures. The most widely used drugs in this category for treatment of children are lamotrigine (LTG), levetiracetam (LVT) and topiramate (TPM). An example of dosage guidelines for these medications and others has recently been published [60].

\section{Lamotrigine (LTG)}

Of the new $2^{\text {nd }}$ generation medications, Lamotrigine is the most frequently prescribed [19]. LTG works mainly by inhibiting sodium voltage gated channels and probably inhibiting calcium voltage gated channels [61]. However, its mechanism of action against absence seizures and bipolar disorders is still unknown [62]. The bioavailability of lamotrigine following oral ingestion is approximately $98 \%$ and it reaches its maximum plasma level after one to three hours. It has a volume of distribution of $1.2 \mathrm{~L} /$ $\mathrm{kg} 2$ and $55 \%$ of lamotrigine is protein bound [23]. LTG's use as a broadspectrum AED has been well documented. According to a study by Brodie et al. [63] and Steiner et al. [64] lamotrigine is equally effective compared to carbamazepine or phenytoin for the treatment of newly diagnosed children with epilepsy. Lamotrigine is highly effective against various types of epileptic seizures, such as absence seizures, infantile seizures and generalised tonicclonic epileptic seizures $[62,65,66]$. However, recent guidelines suggest that it is not as effective in treating absence seizures in children, and either valproic acid or ethosuximide should be the first options for treatment in these cases [67] but is effective as an add-on therapy for generalized tonic-clonic seizures [68]. StevenJohnson syndrome or epidermal necrolysis (potentially lethal skin conditions which usually happen from a drug reaction) are the only serious adverse events $[69,70]$. These can occur within eight weeks from the initiation of therapy. According to Messenheimer [71], the incidence rate of Steven -Johnson syndrome or epidermal necrolysis was 3 in 10000 children treated. Other adverse events include somnolence, dizziness, diplopia, nausea and vomiting
[71]. One study also reported severe toxic effects when taken in overdose, including death [72].

\section{Levetiracetam (LVT)}

LVT's mechanism of action is unknown [2], as it does not have affinity for calcium, potassium or sodium ion channels, nor glutamate and GABA neurotransmitter systems [73]. There are reports that it may work at GABAA receptors indirectly to GABA gated fluxes and may also work on calcium gated channels [74]. It is absorbed rapidly and completely following oral administration2 and reaches its peak plasma concentration one hour after administration [75]. In children, the elimination half-life is from five to seven hours, as it is not metabolised via the liver and is mainly bound to protein [2]. It is converted into inactive metabolites via enzymatic hydrolysis and 93 per cent of the given dose is excreted renally within 24 hours [76]. Levetiracetam has been found to be effective in the treatment of focal-onset seizures, benign epilepsy and generalised epilepsy [77]. In an open-label study by Coppola et al. [78] on 21 children with benign epilepsy aged from 5 to 13 years, it was found that $19(90.5 \%)$ children were seizure free during the follow-up period from 12 to 24 months (mean 18.5 months). von Stuelpnagel et al. [79] found that LVT was effective in the treatment of refractory epilepsy in children and adolescents (mean age was 10.6 years). It has recently been suggested that LVT is effective both as an add-on therapy for focal epilepsy in children less than 4 years of age [68], and for the safe treatment of neonatal seizures [80]. It is also the most commonly prescribed medication for patients less than three years of age [80]. Another recent study suggests that it is beneficial for the safe treatment of patients with autism spectrum disorder and may in fact improve cognitive and behavioural function [81].

Generally, it appears to be well tolerated and safe [82], this is because it has a wide therapeutic index [75]. The most common adverse effects are asthenia, dizziness and somnolence [2]. It also may adversely affect liver enzyme levels [83]. Behavioural problems are also seen, $[19,84]$ such as reversible psychosis associated with auditory and visual hallucinations [85].

\section{Topiramate (TPM)}

Topiramate (TPM) has several mechanisms of action [86]. In vitro studies have revealed that TPM produces its action by blocking sodium channels and electrogenesis of $\mathrm{N}$ and L type of calcium ions [87]. It is thought to have a novel mode of action on GABA receptors leading to enhancement of its inhibitory effect [88]. Topiramate may also have a role in selective blockage of AMPA/Kainate which is a subtype of glutamate receptors [89]. Topiramate is absorbed rapidly from the gastrointestinal tract with bioavailability of approximately 80 to $95 \%$ [23]. After oral administration, its peak plasma levels are reached after one to four hours [23]. Doose et al. [90] showed that topiramate had linear absorption pharmacokinetics at a dose of $100 \mathrm{mg}$ to 400 mg per day. TPM has minimal protein binding of $15 \%$. In adults, the elimination half-life is 18.5 hours, while it is $50 \%$ greater in 
children [91]. Topiramate has a broad-spectrum effectiveness against various forms of childhood epilepsy [2,92]. It has been found to be effective as a first line treatment of epilepsy in both adults and children. In a randomised controlled study evaluating the efficacy of topiramate as a first line of epilepsy treatment, Arroyo and colleagues [93] evaluated the effects of two doses of topiramate: $400 \mathrm{mg}$ and $50 \mathrm{mg}$ per day. They found that after six months, topiramate was effective in $83 \%$ of children who received $400 \mathrm{mg}$ per day and $71 \%$ in children receiving $50 \mathrm{mg}$ per day. Topiramate has the ability to control seizures associated with Lennox-Gastaut disorder [94]. Cognitive impairment is one of the dominant adverse events in school age children. The development of this adverse effect varies between individuals, while it is considered a leading cause for treatment discontinuation [95]. Other adverse events include anorexia, paraesthesia, metabolic acidosis, weight loss, nephrocalcinosis and nephrolithiasis (kidney stones) $[96,97]$.

\section{Antiepileptic Drugs (AEDs) and Adverse Events (AEs)}

Adverse events due to AEDs can be divided into two types: Type A which are related to the pharmacology of the drug and type $B$ that pertain to idiosyncratic adverse events, with adverse effects more prevalent in polytherapy. The various adverse events have been reviewed in the recent literature [97-100]. Type A adverse events are often predictable and occur at the start of treatment and can be avoided by minimising and/or titrating the starting dose slowly. Idiosyncratic reactions, such as hypersensitivity, have been found to occur due to cytoxic or immunological reactions triggered by specific medications or their metabolites. Type B adverse events are unpredictable and may occur with prolonged AEDs treatment at any time [98]. The most common AEDs adverse events are related to central nervous system (CNS), bone and soft tissues, and metabolic events.

\section{Central Nervous System (CNS)}

The Central Nervous System (CNS) AEs are common during treatment using AEDs and occur more frequently in children with focal epilepsy. Of the 1st generation AEDs, phenobarbital (PB) has the highest potential for causing cognitive adverse events. Cognitive impairment by PB include attention reduction, delay of reaction time, impairment of short-term memory and reduction of visual-locative performance. PB can also cause hyperactivity and aggressiveness and language impairment. Psychiatric AEs such as irritability, behavioural changes and depression also occur commonly in children receiving AEDs. A past history of psychiatric disorder is a major risk factor; thus, children with previous psychiatric conditions are at a higher risk.

\section{Bone adverse effects}

Bone related AEs are common in paediatric patients with epilepsy. Long term treatment with AEDs is often associated with a reduction in bone density. Moreover, it has been found that a defect in bone mineral density can be worsened by limited physical activities that may occur due to focal neurological abnormalities and preventing patients from physical activity due to fear of seizure recurrence may also increase the possibility of developing bone adverse effects. AEDs including carbamazepine (CBZ), phenytoin (PHT), primidone (PRM) and phenobarbital (PB) are thought to increase vitamin D breakdown leading to osteomalacia and raised bone turnover. Therefore, paediatric patients treated with AEDs for prolonged periods may be provided with vitamin $\mathrm{D}$ and calcium as prophylaxis in addition to regular monitoring of bone density using bone densitometry.

\section{Muscle and soft tissues change}

Other adverse events that are often associated with certain AEDs are muscle and soft tissue changes [100]. Fibrosing disorders are known to be associated with long treatment with phenobarbital (PB) [2]. Chronic phenytoin (PHT) therapy can cause gum hypertrophy [100]. However, adequate dental and mouth hygiene can minimise this adverse event.

\section{Metabolic adverse effects}

The effect of epilepsy and AEDs on metabolic functions is complicated. Weight gain is considered a common metabolic adverse effect associated with gapabentine, pregabalin, valproic acid and vigabatrin [99]. On the contrary, weight loss may be associated with topiramate and zonisamide [99]. Metabolic acidosis may be associated with AEDs with carbonic anhydrase inhibitory effects.

\section{Summary}

Epilepsy is one of the most common neurological disorders requiring long term treatment. Antiepileptic drugs are considered the mainstay of epilepsy treatment, with the number of available AEDs increasing dramatically over the last two decades. Consequently, the use of these medications in children has also increased, and so have the complications, leading to growing concerns about the safety of these drugs. Determination of AEDs safety is complicated, thus, a sound understanding of the disease itself and the mechanisms of action of the available AEDs is of paramount importance. There are two types of epilepsy treatment regimens, including monotherapy and polytherapy. Monotherapy is considered the most rational treatment of epilepsy in children largely due to the high incidence rate of adverse events with polytherapy. There are now numerous antiepileptic drugs available, however when it comes to treating children, the majority of neurologists prefer 1st generation AEDs due to their proven use and track record in the paediatric population. Assessment of incidence, severity and influence of AEs on some of the most effective methods remain of paramount importance for drug safety evaluation and further clinical studies would provide invaluable information to the practicing pediatric neurologist as the number of treatment possibilities continues to grow.

\section{Acknowledgement}

Author would like to appreciate the great assistance of the authors of the included studies and their support. 


\section{References}

1. Guerrini R (2006) Epilepsy in children. The Lancet 367(9509): 499524.

2. Wallace SJ, Farrell K (2004) Epilepsy in Children. $2^{\text {nd }}$ Edn.

3. Newacheck PW, Taylor WR (1992) Childhood chronic illness: prevalence, severity, and impact. Am J Public Health 82(3): 364-371.

4. Solomon N, McHale K (2012) An overview of epilepsy in children and young people. Nurs Child Young People 24(6): 28-35.

5. Sayers J (2001) The world health report 2001-Mental health: new understanding, new hope. Bulletin of the World Health Organization 79(11): $\quad 1085$.

6. Angeles DK (1981) Proposal for revised clinical and electroencephalographic classification of epileptic seizures. Epilepsia 22(4): 489-501.

7. (1989) Commission on Classification ILAE, Terminology. Proposal for revised classification of epilepsies and epileptic syndromes. Epilepsia 30(4): 389-399.

8. Trevathan E (2003) The diagnosis of epilepsy and the art of listening. Neurology. AAN Enterprises 61(12): 13-14.

9. Kuzniecky RI, Knowlton RC (2002) Neuroimaging of epilepsy. In: Seminars in neurology 279-288.

10. Oguni H (2004) Diagnosis and treatment of epilepsy. Epilepsia 45(8): 13-16.

11. Duncan JS (1997) Imaging and epilepsy. Brain 120(2): 339-377.

12. Dulac $O$ (2005) Issues in paediatric epilepsy. Acta Neurol Scand 112: 9-11.

13. Brodie MJ (2010) Antiepileptic drug therapy the story so far. Seizure 19(10): 650-655.

14. Brodie MJ, Kwan P (2012) Newer drugs for focal epilepsy in adults. BMJ 344-345.

15. LaRoche SM (2007) A new look at the second-generation antiepileptic drugs: a decade of experience. Neurologist 13(3): 133-139.

16. White HS, Smith MD, Wilcox KS (2007) Mechanisms of action of antiepileptic drugs. Int Rev Neurobiol 81: 85-110.

17. Perucca E (2001) Clinical pharmacology and therapeutic use of the new antiepileptic drugs. Fundam Clin Pharmacol 15(6): 405-417.

18. (2004) NICE. The diagnosis and management of the epilepsies in adults and children in primary and secondary care.

19. Egunsola O, Choonara I, Sammons HM (2017) Anti-epileptic drug utilisation in paediatrics: a systematic review. BMJ Paediatr open 1(1): e000088.

20. Perucca P, Gilliam FG, Schmitz B (2009) Epilepsy treatment as a predeterminant of psychosocial ill health. Epilepsy Behav. 15(1): 46-50.

21. Sheth RD, Gidal BE, Hermann BP (2006) Pathological fractures in epi lepsy. Epilepsy Behav 9(4): 601-605.

22. Brodie MJ, Dichter MA (1997) Established antiepileptic drugs. Seizure 6(3): 159-174.

23. Johannessen SI, Tomson T (2006) Pharmacokinetic variability of newer antiepileptic drugs. Clin Pharmacokinet 45(11): 1061-1075.

24. Deckers CLP, Hekster YA, Keyser A, Van Lier HJJ, Meinardi H, et al. (2001) Monotherapy versus polytherapy for epilepsy: a multicenter double-blind randomized study. Epilepsia 42(11): 1387-1394.

25. Perucca E (2003) Current trends in antiepileptic drug therapy. Epilepsia 44(4): 41-47.
26. Schmidt D, Gram L (1995) Monotherapy versus polytherapy in epilepsy. CNS Drugs 3(3): 194-208.

27. Shorvon SD (2005) Handbook of epilepsy treatment: forms, causes and therapy in children and adults.

28. Shorvon S (2010) Handbook of epilepsy treatment.

29. Pellock JM (1998) Treatment of seizures and epilepsy in children and adolescents. Neurology 51(4): 8-14.

30. Wang L, Wang X (2002) Pharmacokinetic and pharmacodynamic effects of clonazepam in children with epilepsy treated with valproate: a preliminary study. Ther Drug Monit 24(4): 532-536.

31. Mirelesh R, Leppik IE (1985) Valproate and clonazepam comedication in patients with intractable epilepsy. Epilepsia 26(2): 122-126.

32. Dreifuss FE, Sato S (1982) Clonazepam. Antiepileptic drugs. 737-752.

33. Shorvon SD (1998) The use of clobazam, midazolam, and nitrazepam in epilepsy. Epilepsia 39(1): 15-23.

34. Wyllie E, Wyllie R, Cruse RP, Rothner AD, Erenberg G (1986) The mechanism of nitrazepam-induced drooling and aspiration. $N$ Engl J Med 314(1): 35-38.

35. Rintahaka PJ, Nakagawa JA, Shewmon DA, Kyyronen P, Shields WD (1999) Incidence of death in patients with intractable epilepsy during nitrazepam treatment. Epilepsia 40(4): 492-496.

36. Ambrósio AF, Soares-da-Silva P, Carvalho CM, Carvalho AP (2002) Mechanisms of action of carbamazepine and its derivatives, oxcarbazepine, BIA 2-093, and BIA 2-024. Neurochem Res 27(1-2): 121130.

37. Ambrósio AF, Silva AP, Malva J0, Soares-da-Silva P, Carvalho AP, et al. (2001) Inhibition of glutamate release by BIA 2-093 and BIA 2-024, two novel derivatives of carbamazepine, due to blockade of sodium but not calcium channels. Biochem Pharmacol 61(10): 12711275.

38. Dailey JW, Reith MEA, Yan Q-S, Li M-Y, Jobe PC (1997) Anticonvulsant doses of carbamazepine increase hippocampal extracellular serotonin in genetically epilepsy-prone rats: dose response relationships. Neurosci Lett 227(1): 13-16.

39. Skerritt JH, Davies LP, Johnston GAR (1983) Interactions of the anticonvulsant carbamazepine with adenosine receptors. 1. Neurochemical studies. Epilepsia 24(5): 634-642.

40. Skerritt JH, Johnston GAR, Chow SC (1983) Interactions of the anticonvulsant carbamazepine with adenosine receptors. 2. Pharmacological studies. Epilepsia 24(5): 643-650.

41. Cornaggia C, Gianetti S, Battino D, Granata T, Romeo A, et al. (1993) Comparative pharmacokinetic study of chewable and conventional carbamazepine in children. Epilepsia 34(1): 158-160.

42. Mattson RH, Cramer JA, Collins JF (1992) A comparison of valproate with carbamazepine for the treatment of complex partial seizures and secondarily generalized tonic-clonic seizures in adults. $\mathrm{N}$ Engl J Med 327(11): 765-771.

43. Pal DK (2006) Phenobarbital for childhood epilepsy: systematic review. Paediatr Perinat Drug Ther 7(1): 31-42.

44. Battino D, Estienne M, Avanzini G (1995) Clinical pharmacokinetics of antiepileptic drugs in paediatric patients. Part I: Phenobarbital, primidone, valproic acid, ethosuximide and mesuximide. Clin Pharmacokinet 29(4): 257-286.

45. Taburet AM, Chamouard C, Aymard P, Chevalier JY, Costil J (1982) Phenobarbital protein binding in neonates. Dev Pharmacol Ther 4: 129-134. 
46. Calandre EP, Dominguez-Granados R, Gomez-Rubio M, Molina-Font JA (1990) Cognitive effects of long-term treatment with phenobarbital and valproic acid in school children. Acta Neurol Scand 81(6): 504-506.

47. Burd L, Kerbeshian J, Fisher W (1987) Does the use of phenobarbital as an anticonvulsant permanently exacerbate hyperactivity? Can J Psychiatry 32(1): 10-13.

48. Tunnicliff G (1996) Basis of the antiseizure action of phenytoin Gen Pharmacol 27(7): 1091-1097.

49. Coté CJ, Lugo RA, Ward RM (2001) Pharmacokinetics and pharmacology of drugs in children. A Pract Anesth infants Child (Edited by Coté CJ, Todres ID, Ryan JF, Goudsouzian NG) Philadelphia (USA), WB Saunders Co.

50. Painter MJ, Alvin J (2001) Neonatal seizures. Curr Treat Options Neurol 3(3): 237-248.

51. Gupta YK, Gupta M (2006) Post traumatic epilepsy: a review of scientific evidence. Indian J Physiol Pharmacol 50(1): 7-16.

52. Suneja B, Chopra S, Thomas AM, Pandian J (2016) A clinical evaluation of gingival overgrowth in children on antiepileptic drug therapy. J Clin diagn Res 10(1): 32-36.

53. Löscher W. Basic pharmacology of valproate. CNS Drugs 16(10): 669-694.

54. Cramer JA, Mattson RH (1979) Valproic acid: in vitro plasma protein binding and interaction with phenytoin. Ther Drug Monit 1(1): 105-116.

55. Gram L, Flachs H, Wurtz-Jørgensen A, Parnas J, Andersen B (1979) Sodium valproate, serum level and clinical effect in epilepsy: a controlled study. Epilepsia 20(3): 303-311.

56. Levy RH, Shen DD, Abbott FS, Riggs KW, Hachad H (2002) Valproic acid: chemistry, biotransformation and pharmacokinetics. Antiepileptic drugs 5: 780-800.

57. Davis R, Peters DH, McTavish D (1994) Valproic acid. A reappraisal of its pharmacological properties and clinical efficacy in epilepsy. Drugs 47(2): 332-372.

58. Lagace DC, O’Brien WT, Gurvich N, Nachtigal MW, Klein PS (2004) Valproic acid: how it works. Or not. Clin Neurosci Res 4(3-4): 215-225.

59. George IC (2017) How do you treat epilepsy in pregnancy? Neurol Clin Pract 7(4).

60. Reimers A, Berg JA, Burns ML, Brodtkorb E, Johannessen SI, et al. (2018) Reference ranges for antiepileptic drugs revisited: a practical approach to establish national guidelines. Drug Des Devel Ther 12: 271-280.

61. Stefani A, Spadoni F, Bernardi G (1997) Voltage-activated calcium channels: targets of antiepileptic drug therapy? Epilepsia 38(9): 959-965.

62. Frank LM, Enlow T, Holmes GL, Manasco P, Concannon S, et al. Lamictal (lamotrigine) monotherapy for typical absence seizures in children. Epilepsia 40(7): 973-979.

63. Brodie MJ, Richens A, Yuen AWC (1995) Double-blind comparison of lamotrigine and carbamazepine in newly diagnosed epilepsy. UK Lamotrigine/Carbamazepine Monotherapy Trial Group. Lancet 345(8948): 476-479.

64. Steiner TJ, Dellaportas CI, Findley LJ, Gross M, Gibberd FB, et al. (1999) Lamotrigine monotherapy in newly diagnosed untreated epilepsy: a double-blind comparison with phenytoin. Epilepsia 40(5): 601-607.

65. Beran RG, Berkovic SF, Dunagan FM, Vajda FJE, Danta G, et al. (1998) Double-Blind, Placebo-Controlled, Lamotrigine in Treatment-Resistant Generalised Epilepsy. Epilepsia 39(12): 1329-1333.

66. Motte J, Trevathan E, Arvidsson JF V, Barrera MN, Mullens EL, et al. (1997) Lamotrigine for generalized seizures associated with the Lennox--Gastaut syndrome. N Engl J Med 337(25): 1807-1812.

67. Kanner AM, Ashman E, Gloss D, Harden C, Bourgeois B, et al (2018) Practice guideline update summary: Efficacy and tolerability of the new antiepileptic drugs I: Treatment of new-onset epilepsy: Report of the American Epilepsy Society and the Guideline Development, Dissemination, and Implementation Subcommittee of the Am. Epilepsy Curr 91(2): 74-81.

68. Kanner AM, Ashman E, Gloss D, Harden C, Bourgeois B, et al. (2018) Practice guideline update summary: Efficacy and tolerability of the new antiepileptic drugs II: Treatment-resistant epilepsy: Report of the Guideline Development, Dissemination, and Implementation Subcommittee of the American Academy of Neurology. Epilepsy Curr 18(4): 269-278.

69. Jacob S, Nair AB (2016) An updated overview on therapeutic drug monitoring of recent antiepileptic drugs. Drugs R D 16(4): 303316.

70. Hilas O, Charneski L (2007) Lamotrigine-induced Stevens-Johnson syndrome. Am J Heal Pharm 64(3): 273-275.

71. Messenheimer J (2002) Efficacy and safety of lamotrigine in pediatric patients. J Child Neurol 17(2): 34-42.

72. Alabi A, Todd A, Husband A, Reilly J (2016) Safety profile of lamotrigine in overdose. Ther Adv Psychopharmacol 6(6):369-381.

73. Zona C, Niespodziany I, Marchetti C, Klitgaard H, Bernardi G, Margineanu DG (2001) Levetiracetam does not modulate neuronal voltage-gated $\mathrm{Na}+$ and T-type Ca2 + currents. Seizure 10(4): 279-286.

74. Palma E, Ragozzino D, Angelantonio S Di, Mascia A, Maiolino F, et al. (2007) The antiepileptic drug levetiracetam stabilizes the human epileptic GABAA receptors upon repetitive activation. Epilepsia 48(10): 1842-1849.

75. Glauser TA, Mitchell WG, Weinstock A, Bebin M, Chen D, et al. (2007) Pharmacokinetics of levetiracetam in infants and young children with epilepsy. Epilepsia 48(6): 1117-1122.

76. Patsalos PN (2004) Clinical pharmacokinetics of levetiracetam. Clin Pharmacokinet 43(11): 707-724.

77. Zhang L, Wang C, Li W (2018) A meta-analysis of randomized controlled trials on levetiracetam in the treatment of pediatric patients with epilepsy. Neuropsychiatr Dis Treat 14: 769-779.

78. Coppola G, Franzoni E, Verrotti A, Garone C, Sarajlija J, et al. (2007) Levetiracetam or oxcarbazepine as monotherapy in newly diagnosed benign epilepsy of childhood with centrotemporal spikes (BECTS): an open-label, parallel group trial. Brain Dev 29(5): 281-284.

79. von Stuelpnagel C, Holthausen H, Kluger G (2007) Long-term use of levetiracetam in patients with severe childhood-onset epilepsy. Eur J Paediatr Neurol 11(6): 341-345.

80. Han JY, Moon CJ, Youn YA, Sung IK, Lee IG (2018) Efficacy of levetiracetam for neonatal seizures in preterm infants. BMC Pediatr 18(1): 131.

81. Wang M, Jiang L, Tang X (2017) Levetiracetam is associated with decrease in subclinical epileptiform discharges and improved cognitive functions in pediatric patients with autism spectrum disorder. Neuropsychiatr Dis Treat 13: 2321-2326.

82. French J, Edrich P, Cramer JA (2001) A systematic review of the safety profile of levetiracetam: a new antiepileptic drug. Epilepsy Res 47(1-2): 77-90. 
83. Attilakos A, Dinopoulos A, Paschalidou M, Tsirouda M, Prasouli A, et al. (2018) Effect of Levetiracetam Monotherapy on Liver Enzymes and Creatine Kinase Concentrations in Children with Epilepsy: A Prospective Study. J Clin Neurol 14(4): 594-595.

84. Egunsola O, Choonara I, Sammons HM (2016) Safety of Levetiracetam in Paediatrics: a systematic review. PLoS One 11(3): e0149686.

85. Kossoff EH, Bergey GK, Freeman JM, Vining EPG (2001) Levetiracetam psychosis in children with epilepsy. Epilepsia 42(12): 16111613.

86. Patsalos PN (1999) The mechanism of action of topiramate. REV CONTEMP Pharm 10(3): 147-153.

87. Kuzmiski JB, Barr W, Zamponi GW, MacVicar BA (2005) Topiramate inhibits the initiation of plateau potentials in CA1 neurons by depressing R-type calcium channels. Epilepsia 46(4): 481-489.

88. Herrero AI, Del Olmo N, González-Escalada JR, Solís JM (2002) Two new actions of topiramate: inhibition of depolarizing GABAA-mediated responses and activation of a potassium conductance. Neuropharmacology 42(2): 210-220.

89. Kaminski RM, Banerjee M, Rogawski MA (2004) Topiramate selectively protects against seizures induced by ATPA, a GluR5 kainate receptor agonist. Neuropharmacology 46(8): 1097-1104.

90. Doose DR, Walker SA, Gisclon LG, Nayak RK (1996) Single-dose pharmacokinetics and effect of food on the bioavailability of topiramate, a novel antiepileptic drug. J Clin Pharmacol 36(10): 884-891.

91. Battino D, Croci D, Rossini A, Messina S, Mamoli D, et al. (2005) Topiramate pharmacokinetics in children and adults with epilepsy. Clin Pharmacokinet 44(4): 407-416.

This work is licensed under Creative Commons Attribution 4.0 Licens DOI: 10.19080/AJPN.2019.08.555790
92. Knoester PD, Deckers CLP, Termeer EH, Boendermaker AJ, Kotsopoulos IA, et al. A cost-effectiveness decision model for antiepileptic drug treatment in newly diagnosed epilepsy patients. Value Heal 10(3): 173-182.

93. Arroyo S, Dodson WE, Privitera MD, Glauser TA, Naritoku DK, et al. (2005) Randomized dose-controlled study of topiramate as firstline therapy in epilepsy. Acta Neurol Scand 112(4): 214-222.

94. Coppola G, Caliendo G, Veggiotti P, Romeo A, Tortorella G, et al. (2002) Topiramate as add-on drug in children, adolescents and young adults with Lennox-Gastaut syndrome: an Italian multicentric study. Epilepsy Res 51(1-2): 147-153.

95. Lee H-W, Jung D-K, Suh C-K, Kwon S-H, Park S-P (2006) Cognitive effects of low-dose topiramate monotherapy in epilepsy patients: A 1-year follow-up. Epilepsy Behav 8(4): 736-741.

96. Belotti EA, Taddeo I, Ragazzi M, Pifferini R, Simonetti GD, et al. (2010) Chronic impact of topiramate on acid-base balance and potassium in childhood. Eur J Paediatr Neurol 14(5): 445-448.

97. Cramer JA, Mintzer S, Wheless J, Mattson RH (2010) Adverse effects of antiepileptic drugs: a brief overview of important issues. Expert Rev Neurother 10(6): 885-891.1

98. Perucca E, Meador KJ (2005) Adverse effects of antiepileptic drugs. Acta Neurol Scand 181: 30-35.

99. Ben-Menachem E (2007) Weight issues for people with epilepsy-a review. Epilepsia 48(9): 42-45.

100. Mattson RH (1995) Efficacy and adverse effects of established and new antiepileptic drugs. Epilepsia 36(2): 13-26.

\section{Your next submission with Juniper Publishers will reach you the below assets}

- Quality Editorial service

- Swift Peer Review

- Reprints availability

- E-prints Service

- Manuscript Podcast for convenient understanding

- Global attainment for your research

- Manuscript accessibility in different formats

( Pdf, E-pub, Full Text, Audio)

- Unceasing customer service

Track the below URL for one-step submission https://juniperpublishers.com/online-submission.php 